ИЗВЕСТИЯ АКАДЕМИИ НАУК ЭСТОНСКОИ ССР, ТОМ 24 ХИМИЯ * ГЕОЛОГИЯ. 1975, № 1

\title{
РАЗДЕЛЕНИЕ И ОПРЕДЕЛЕНИЕ КОНДЕНСИРОВАННЫХ ФОСФАТОВ МЕТОДАМИ ТОНКОСЛОЙНОЙ ХРОМАТОГРАФИИ И ДЕНСИТОМЕТРИИ
}

Қачественное и количественное определение конденсированных фосфатов в их смесях необходимо при исследованиях в области фосфатов, а также при контроле производства и качества фосфорных солей, удобрений и кислот. Методы колоночной $(\mathrm{KX})$ и бумажной хроматографии (БХ) $\left[{ }^{1-3}\right]$ при массовых анализах из-за своей продолжительности неудобны для разделения фосфатов. При помощи тонкослойной хроматографии (ТCX) получены удовлетворительные результаты на слоях из микрокристаллической целлюлозы [ $\left.{ }^{4}\right]$. Для количественного определения разделенные конденсированные фосфаты переводят гидролизом в ортофосфаты и колориметрируют.

Нами проведено разделение конденсированных фосфатов методом TCX на силикагеле как более дешевом и доступном сорбенте, а также количественное определение их при помощи денситометрии. Применение последнего ускоряет анализ, поскольку содержание $\mathrm{P}_{2} \mathrm{O}_{5}$ определяется непооредственно на хроматограммах по площади и интенсивности окраски пятен. При этом исключаются ошибки, обусловленные снятием отдельных пятен с пластинки.

Для приготовления сорбента использовали технический силикагель КСК. Фракции измельченного силикагеля $(0,40-0,45$ мк и $0,45-0,50$ мк) для удаления примесей обрабатывали соляной кислотой по методикам, разработанным нами ранее [5]. В целях сравнения использовали очищенный силикагель «Вельм» (ФРГ). Для более точной характеристики сорбентов определяли их внешнюю $\left[{ }^{6}\right]$ и общую $\left[{ }^{7}\right]$ удельную поверхность, которые соответственно были равны: KCK-I - 4,4 и $63 \mathrm{~m}^{2} / 2$; KCK-II 3,5 и $75 \mathrm{~m}^{2} / 2$; KCK-III - 1,4 и $71 \mathrm{~m}^{2} / 2$ и «Вельм» - 1,2 и $105 \mathrm{~m}^{2} / 2$.

Суспензию для получения тонких слоев приготовляли из силикагеля кукурузного крахмала и воды методом, описанным ранее [8], и наносили прибором «Дезага» на стеклянные пластинки размером $10 \times 20$ и $20 \times 20 \mathrm{~cm}$. Готовые пластинки сушили на воздухе и хранили в эксикаторе. При хроматографировании использовали инактивированные слои сорбента толщиной $0,15-0,18$ м. (после высушивания) и ненасыщенную паром элюента нормальную камеру фирмы «Шандон».

Растворы орто-, пиро-, триполи-, тримета- и тетраметафосфатов натрия приготовляли с весовым содержанием $\mathrm{P}_{2} \mathrm{O}_{5} 0,5 \%$. Пробы наносили в один прием по 2 мкл на стартовую линию в 15 мм от края пластинок. 


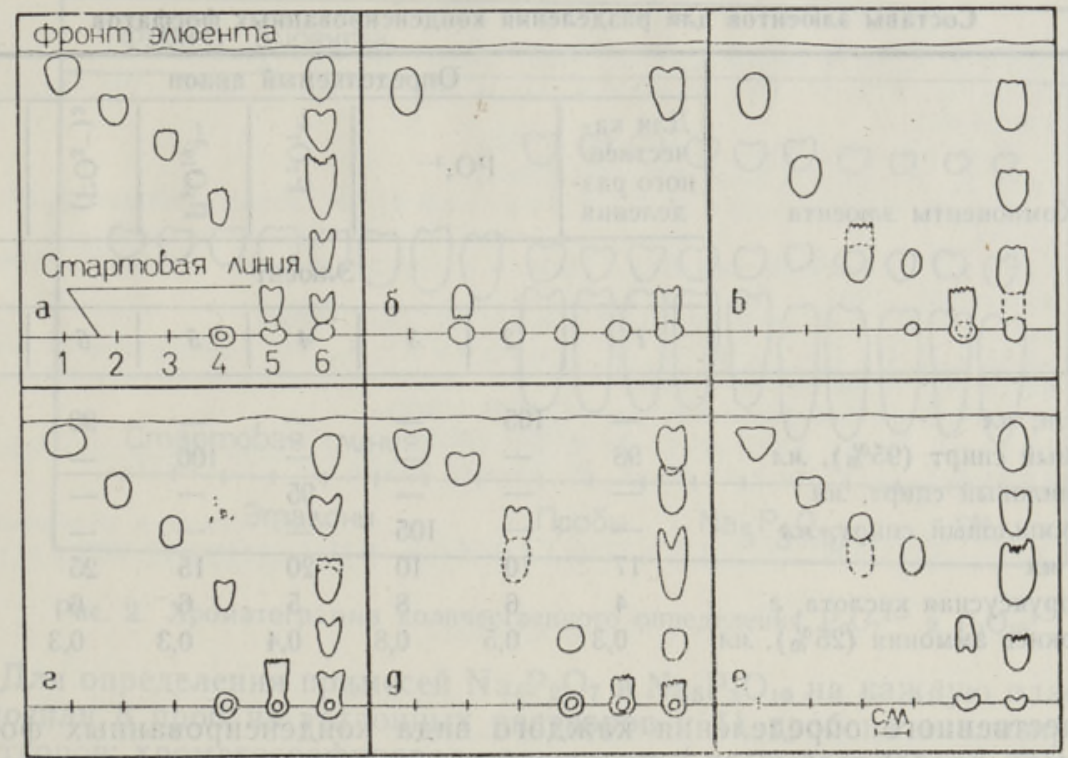

Рнс. 1. Хроматограммы конденсированных фосфатов при разделении элюентами $I(a), 3(6), 4(8), 5(2), 6(\partial), 7(e)$, приведенными в таблице. Пробы нанесены по порядку: $I-\mathrm{PO}_{4}^{3-}, 2-\mathrm{P}_{2} \mathrm{O}_{7}{ }^{4-}, 3-\mathrm{P}_{3} \mathrm{O}_{10}{ }^{5-}, 4-$ $\left(\mathrm{PO}_{3}^{-}\right)_{3}, 5-\left(\mathrm{PO}_{3}^{-}\right)_{4}, 6-$ смесь.

Одновременно в одной камере хроматографировали четыре пластинки (размером $10 \times 20$ cм) - каждая со слоем различного силикагеля (KCK-I, KCK-II, KCK-III и «Вельм») - при помощи элюентов, использующихся в БХ $\left[{ }^{4}, 9\right]$ и ТСХ на микрокристаллической целлюлозе. Высота подъема элюента составляла $80-85$ мм от стартовой линии. После элюнрования слои тщательно сушили под тягой и опрыскивали проявителем [4]. Восстановителем $\left[{ }^{4}\right]$ опрыскивали примерно через час, т. е. когда слой высох и проявились синие контуры пятен.

По хроматограммам выяснилось, что ни один из использованных элюентов не пригоден для количественного определения. В кислотных элюентах значения $R_{f}$ * фосфатов находились в пределах $0,62-0,92$, что не позволяет разделить их смеси. При щелочных элюентах впереди и позади пятен были длинные хвосты. Самыми компактными были пятна при кислотных элюентах на слое из силикагеля КСК-III, исходя из чего дальнейшие исследования проводили с кислотными элюентами на слоях этого силикагеля.

При разработке подходящих элюентов было установлено, что значения $R_{f}$ увеличиваются с повышением содержания воды в элюенте, а компактность пятен связана с содержанием трихлоруксусной кислоты и аммиака. От растворителя зависят также относительные скорости движения фосфатов. Так, в элюентах на базе $\mu$-пропилавого и $u з о$-пропилового спирта триполи- и триметафосфат двигались с одинаковыми, а на основе диоксана и этилового спирта с различными скоростями. В элюенте $I$ (таблица) на базе этанола разделялись все исследованные конденсированные фосфаты (рис. 1), но эта хроматограмма не пригодна для точного количественного определения методом денситометрии, поскольку пятна на ней расположены относительно близко друг к другу. Поэтому для элюента.

* $R_{f}$ - отношение расстояния пятна от стартовой линии к расстоянию фронта 
Составы элюентов для разделения конденсированных фосфатов

\begin{tabular}{|c|c|c|c|c|c|c|c|}
\hline \multirow{4}{*}{ Компоненты элюента } & \multicolumn{7}{|c|}{ Определяемый анион } \\
\hline & \begin{tabular}{|c|} 
Для ка- \\
чествен- \\
ного раз- \\
деления
\end{tabular} & \multicolumn{2}{|c|}{$\mathrm{PO}_{4}{ }^{3-}$} & 0 & $\begin{array}{l}1 \\
0 \\
0 \\
0\end{array}$ & 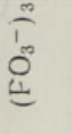 & $\overbrace{i}^{1}$ \\
\hline & \multicolumn{6}{|c|}{ Элюент } & \multirow[b]{2}{*}{7} \\
\hline & 1 & 2 & 3 & 4 & 5 & 6 & \\
\hline Диоксан, мл & - & 105 & 一 & 一 & - & 90 & - \\
\hline Этиловый спирт $(95 \%), м \Omega$ & 98 & 一 & 一 & 一 & 100 & - & - \\
\hline н-Пропиловый спирт, мл & 一 & 一 & - & 95 & 一 & 一 & - \\
\hline изо-Пропиловый спирт, $м л$ & 一 & - & 105 & - & - & - & 85 \\
\hline Вода, мл & 17 & 10 & 10 & 20 & 15 & 25 & 30 \\
\hline Трихлоруксусная кислота, 2 & 4 & 6 & 8 & 5 & 6 & 6 & 5 \\
\hline Гидроокись аммония $(25 \%), м /$ & 0,3 & 0,5 & 0,8 & 0,4 & 0,3 & 0,3 & 0,8 \\
\hline
\end{tabular}

количественного определения каждого вида конденсированных фосфатов были разработаны селективные элюенты, составы которых приведены в таблице. Элюенты 2 и 3 являются селективными в отношении ортофосфата (другие остаются на стартовой линии): $R_{f}=0,85$, время подъема элюента на 85 мм соответственно 120 и 180 мин. Хроматограммы, полученные при использовании других элюентов, приведены на рис. 1. Общим для всех хроматограмм является то, что пятна различных фосфатных анионов, полученные хроматографированием смеси фосфатов, имеют более низкое значение $R_{f}$, чем при элюировании того же фосфата в чистом виде. Это объясняется эффектом взаимного вытеснения фосфатов при хроматографировании.

Практическими объектами анализа были технический триполифосфат натрия (пробы получены из НИУИФ) и продукты кислотно-термической переработки Маардуского фосфорита $\left[{ }^{10}\right]$. В первом объекте были установлены примеси пиро- и ортофосфата, во втором - пирофосфата.

При определении пирофосфата денситометрически сначала выясняли пределы линейной зависимости между содержанием $\mathrm{P}_{2} \mathrm{O}_{5}$ в пятне и площадью пиков денситограмм, а затем вычисляли случайную ошибку. Для этого на восьми пластинках размером $20 \times 20$ см элюентом 4 хроматографировали эталонные растворы с различным содержанием пирофосфата натрия (от 1,1 до 4,0 мкг/мкл $\mathrm{P}_{2} \mathrm{O}_{5}$ ). Поглощение пятен на хроматограммах измерялось двухлучевым регистрирующим и интегрирующим денситометром «Хромоскан». Пятна сканировали в направлении движения элюента (непосредственно после высушивания пластинок) при длине волны 620 нм щелью длиной 10 мм. Денситограммы регистрировали на миллиметровой бумаге и подсчитывали площади пиков. Случайную ошибку $(\varepsilon)$ градуировочной прямой

$$
I=a+80 b W
$$

где $I$ - площадь пика денситограммы, $\mu^{2} ; W$ - количество $\mathrm{P}_{2} \mathrm{O}_{5}$ в пятне, мкг; $a$ и $b$ - постоянные; 80 - масштабный фактор, обеспечивающий угол близкий к $45^{\circ}$, вычисляли методом регрессий по методике, описанной ранее [1"1. По данным восьми хроматограмм при однократном нанесении анализируемой пробы $\bar{\varepsilon}= \pm 8 \%$. Неизвестную пробу наносили на пластинки 4 раза, что уменьшало $\bar{\varepsilon}$ до $\pm 5 \%$. 


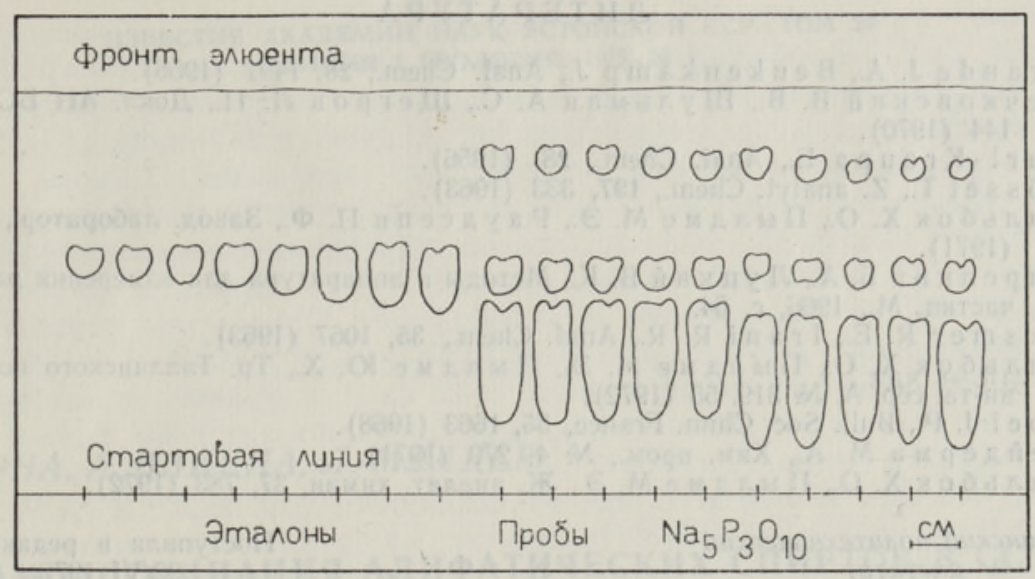

Рнс. 2. Хроматограмма количественного определения $\mathrm{P}_{2} \mathrm{O}_{7}^{4-}$ в $\mathrm{P}_{3} \mathrm{O}_{10}{ }^{5-}$.

Для определения примесей $\mathrm{Na}_{4} \mathrm{P}_{2} \mathrm{O}_{7}$ в $\mathrm{Na}_{5} \mathrm{P}_{3} \mathrm{O}_{10}$ на каждую пластинку наносили 8 проб из эталонных растворов и 11 проб из анализируемых растворов; хроматографировали элюентом 4 на высоту $80 \mathrm{mм}$. Характерная хроматограмма приведена на рис. 2. По площадям пиков денситограмм эталонных пятен строили калибровочный график, по которому определяли содержание $\mathrm{P}_{2} \mathrm{O}_{5}$ в пятнах пирофосфата анализируемых проб. Аналогично определяли примесь $\mathrm{PO}_{4}{ }^{3-}$ (при этом эталонные растворы $\mathrm{PO}_{4}{ }^{3-}$ содержали $\mathrm{P}_{2} \mathrm{O}_{5}$ от 1 до 5 мкг/мкл) и хроматографировали элюентом 3. Все анализируемые пробы $\mathrm{Na}_{5} \mathrm{P}_{3} \mathrm{O}_{10}$ содержали $\mathrm{Na}_{4} \mathrm{P}_{2} \mathrm{O}_{7}$ в среднем $8 \%$ и $\mathrm{Na}_{2} \mathrm{HPO}_{4}-0,50 \%$.

При анализах продуктов кислотно-термической переработки Маардуского фосфорита к навескам около 0,15 г прибавляли 7 г катионита «Дауекс-50W» в Н-форме, 25 мл воды и перемешивали магнитной мешалкой при комнатной температуре в течение 2 . Раствор. отделяли фильтрованием, а остаток на фильтре промывали 25 мл воды. Фильтрат нейтрализовали раствором $\mathrm{NaOH}$ до $\mathrm{pH} 8,0$ и выпаривали под вакуумом при $20^{\circ} \mathrm{C}$ до требуемого объема (около $10 \mathrm{M} /$ ). Пробы, нагретые при 300,500 и $700^{\circ}$, содержали $\mathrm{P}_{2} \mathrm{O}_{5}$ в виде пирофосфата соответственно 2,0 , 4,8 и $3,9 \%$.

Основными преимуществами ТСХ на силикагеле перед БХ оказались компактность пятен и относительно короткая высота подъема элюента $(85$ мм), требуемая для разделения исследуемой смеси конденсированных фосфатов. Время хроматографирования при этом в зависимости от элюента составляло 100-180 мин. Денситометрическое определение фосфатов осуществляется просто и быстро, так как не требует отделения пятен, экстракции и гидролиза как, например, колориметрия. Поскольку точность определения невелика - $\pm 5 \%$, метод не пригоден для определения основного компонента, а вполне применим для примесей.

\section{Выводы}

1. ТСХ на слоях силикагеля КСК применима для качественного определения смесей орто-, пиро-, триполи-, тримета- и тетраметафосфата и количественного определения методом денситометрии.

2. Простая и не требующая длительного времени методика, разработанная нами, пригодна для массовых определений примесей конденсированных фосфатов в любом фосфате (основном компоненте). 
1. Gra n de J. A., B eukenka m p J., Anal. Chem., 28, 1497 (1956).

2. Печковский В. В., Шульман А. С., Щегров Л. Н., Докл. АН БССР, 14, $144(1970)$.

3. Ka r l-Kroup a E., Anal. Chem., 28 (1956).

4. Rö s s e l T., Z. analyt. Chem., 197, 333 (1963).

5. В и льбок Х. О., П лд д е М. Э., Р а уд с е п п П. Ф., Завод. лаборатор., 37, 787 (1971).

6. К аюр е к и н Б. А., Л у ц и й В. К., Методы и аппаратура для измерения размеров частиц. М., 1966 , с. 54.

7. Mesmer R. E., I r a n i R. R., Anal. Chem., 35, 1067 (1963).

8. В ильбок Х. О., П ллд м е М. Э., Пылд м Ю. Х., Тр. Таллинского политехн. ин-та, сер. А, № 319, 55 (1972).

9. E b e 1 J. P., Bull. Soc. Chim. France, 35, 1663 (1968).

10. В ейд е р м а М. А., Хим. пром., № 4, 279 (1971).

11. В ильбок Х. О., П ылдм е М. Э., Ж. аналит. химии, 37, 783 (1972).

таллинский политехнический институт
Поступила в редакцию 22/VI 1973

\section{H. VILBOK, M. POLDME, JUta POLDME, P. RAUDSEPP}

\section{KONDENSEERITUD FOSFAATIDE LAHUTAMINE JA MAARAMINE OHUKESE KIHI KROMATOGRAAFIA JA DENSITOMEETRIA ABIL}

Silikageeli KSK kihil lahutati mitmesuguste modifitseeritud happeliste eluentide abil orto-, püro-, tripolü-, trimeta- ja tetrametafosfaatide segud. Kvantitatiivseks densitomeetriliseks määramiseks kasutati selektiivseid eluente. Analüüsiti tehnilist naatriumtripolüfosfaati ja vees lahustumatuid kaltsiumfosfaate. Viga püro- ja ortofosfaadi lisandite määramisel tripolüfosfaadis oli $\pm 5 \%$.

\section{H. VILBOK, M. POLDME, JUTa POLDME, P. RAUDSEPP}

\section{SEPARATION AND DETERMINATION OF CONDENSED PHOSPHATES BY THIN LAYER CHROMATOGRAPHY AND DENSITOMETRY}

Mixtures of ortho-, pyro-, tri-, trimeta- and tetrametaphosphates were separated by various acidic modified solvents on silica gel KSK. For quantitative densitometric determination, selective solvents were used. The analysis of commercial sodium triphosphate and insoluble calcium phosphates has been described. The error of determination of traces of pyro- and orthophosphate in triphosphate was found to be less than \pm 5 per cent. 